\title{
Ultrasonic tips as an auxiliary method for the instrumentation of oval-shaped root canals
}

\author{
Melissa Esther RIVERA-PEÑA ${ }^{(a)}$ \\ Marco Antônio Húngaro DUARTE(a) iD \\ Murilo Priori ALCALDE(a) \\ Renan Diego FURLAN(a) \\ Marcus Vinicius Reis SÓ(a) iD \\ Rodrigo Ricci VIVAN(a) \\ (a) Universidade de São Paulo - USP, Bauru \\ School of Dentistry, Department of \\ Operative Dentistry, Endodontics and \\ Dental Materials, Bauru, SP, Brazil.
}

Declaration of Interests: The authors certify that they have no commercial or associative interest that represents a conflict of interest in connection with the manuscript.

Corresponding Author:

Rodrigo Ricci Vivan

E-mail: rodrigo.vivan@fob.usp.br

Submitted: July 23, 2018

Accepted for publication: November 26, 2018

Last revision: January 10, 2019
Abstract: To evaluate the influence of novel ultrasonic tips as an auxiliary method for the rotary preparation of flattened/oval-shaped canals. Fortyfive mandibular incisors were selected and divided into one of three experimental groups ( $n=15)$ : Group PFCP - ProDesign Logic 25/.05 + Flatsonic + Clearsonic + Prodesign Logic 40/.01; Group FCP - Flatsonic + Clearsonic + ProDesign Logic 40/.01; and Group PP - Prodesign Logic 25/.05 + Prodesign Logic 40/.05. The teeth were scanned preoperatively and postoperatively using microcomputed tomography. The percentage values for increase in volume, non-instrumented surface area, dentin removal, degree of canal transportation, and centering ratio between the experimental groups were examined. Data were analyzed using the non-parametric Kruskal-Wallis and Dunn's tests $(p<0.05)$. Group PFCP showed the greatest volume increase in the total portion of the root canal and the lowest percentage of non-instrumented surface area. Regarding the degree of transportation in the buccolingual direction, statistically significant differences between groups PFCP and PP were observed at the coronal third of the canal. In the mesiodistal direction, no statistically significant differences were observed at the coronal, middle, and apical thirds. As for the centering ratio, statistically significant differences were found in the buccolingual direction. In the mesiodistal direction, no statistically significant differences were observed at the coronal, middle, and apical thirds. The use of novel ultrasonic tips combined with rotary instruments in group PFCP provided a significant increase in volume and reduced the percentage of non-instrumented areas during the preparation of flattened/oval-shaped canals.

Keywords: Endodontics; Ultrasonics; Root Canal Preparation; X-Ray Microtomography.

\section{Introduction}

The literature has reported the prevalence of mandibular incisors with flat oval-shaped root canals. . $^{1,2,3,4,5}$ The presence of these anatomical features has been associated with complications during instrumentation with hand and engine-driven instruments, hindering the cleanliness of the root canal system. $6,7,8,9,10,11,12,13$ Nickel-titanium (NiTi) instrumentation tends to maintain a self-centered position during rotation, creating a circular bulge and producing a smear layer in the prepared portions of 
the root canal walls, whereas pulp remnants and infected dentin remain in the areas untouched by endodontic files. ${ }^{11}$ Microcomputed tomography $(\mu \mathrm{CT})$ studies have revealed that more than half of the root canal walls (ranging from $59.6 \%$ to $79.9 \%$ ) remain unprepared in oval-shaped canals, irrespective of the instrumentation technique. ${ }^{14}$ Microcomputed tomography imaging technology allows detailed visualization of the morphological characteristics of teeth. ${ }^{4,14,15}$ Thus, $\mu \mathrm{CT}$ has been proposed as a suitable outcome parameter to compare the shaping ability of different endodontic instruments and techniques, offering promising results. ${ }^{14}$

In controlled memory (CM) technology, endodontic instruments are subjected to a special heat treatment process after machining of conventional NiTi wire, including high martensitic crystal content in order to improve their mechanical behavior. ${ }^{16}$ Recently, CM rotary files, ProDesign Logic 25/.05 and 40/.05 (Easy Equipamentos Odontológicos, Belo Horizonte, Brazil) have been introduced. In addition, the manufacturer presented a new $\mathrm{CM}$ rotary file with size 40 and taper 01. On the other hand, ultrasonic instrumentation has been proposed in the literature as an auxiliary approach, in combination with endodontic instruments, for improving the cleanliness of the root canal system. ${ }^{17,18}$ Two novel ultrasonic tips (Flatsonic and Clearsonic, Helse Ultrasonic, Santa Rosa de Viterbo, Brazil) with an arrow section have been proposed as an alternative method for the instrumentation of flattened/oval-shaped canals. We expect that the combination of different instrumentation techniques will provide adequate shaping of the root canal system by enhancing preparation of the root canal surface. ${ }^{17,18}$ The aim of this study was to evaluate the influence of novel ultrasonic tips as an auxiliary method for the rotary preparation of flattened/oval-shaped canals. The null hypothesis tested was that these novel ultrasonic tips would not influence the root canal preparation of flattened/oval-shaped canals.

\section{Methodology}

Sample size was calculated using the $G^{*}$ Power v3.1 for Mac (Heinrich Heine, Universität Düsseldorf) by selecting the one-way fixed effects ANOVA. The data from a previous study on oval-shaped root canal instrumentation were used and the effect size was established in the present study $(=0.65) \cdot{ }^{19}$ An alpha error of 0.05 and a beta power of 0.95 were also stipulated. A total of 14 specimens per group were indicated as the ideal size required for noting significant differences. An additional specimen per group was used to compensate for possible loss during the experiments.

Forty-five mandibular incisors extracted from patients in a Brazilian population for reasons unrelated to this study were acquired after approval of the study protocol by the Human Research Ethics Committee (CEP 2.112.063). Teeth with two root canals, with an open apex, or with previous endodontic treatment were excluded. The samples were scanned before and after the instrumentation protocols with a Skyscan 1174 microcomputed tomography system (BrukermicroCT, Kontich, Belgium). The parameters used were $50 \mathrm{kV}, 800 \mathrm{~mA}$, and a voxel size of $16.8 \mu \mathrm{m}$. The system included a charge-coupled device camera (1304_1024 pixels). Radiographic images of each sample were reconstructed by using the NRecon software (BrukermicroCT Kontich, Belgium). Three-dimensional models were reconstructed after the segmentation and binarization processes with CTAn v.1.12 software (Bruker-microCT Kontich, Belgium). CTVol v.2.2.1 and Data Viewer software programs (Bruker-micro CT Kontich, Belgium) were used for visualizing and evaluating the internal anatomy according to a novel classification..$^{20}$ Only ${ }^{1} \mathrm{TN}^{1}$ mandibular incisors with an oval-shaped configuration were selected. An oval canal was identified when the buccolingual diameter was twice as long as or longer than the mesiodistal diameter. ${ }^{21}$ CTan v.1.12 software (Bruker-microCT Kontich, Belgium) was also used to calculate the volume of the samples of all root canal walls (mesial/ distal/buccal/lingual).

During the experimental procedures, all the specimens were placed in a custom-made metallic muffle prepared for each specimen and fixed internally with silicone impression material to simulate clinical conditions. Access cavities were performed with a size 2 high-speed diamond bur (FG 1012 KG Sorensen, São Paulo, Brazil) under water spray. The working length was determined by placing a size 15 
K-file (Dentsply Maillefer, Ballaigues, Switzerland) into the canal until it was visible at the root apex under the dental operating microscope (Alliance Microscopia, São Carlos, Brazil), and was established $1 \mathrm{~mm}$ short of this length. The samples $(n=45)$ were divided into one of the three experimental groups according to the anatomy of the specimens and to the preparation technique. An endodontic specialist performed all the procedures under a dental operating microscope at $6 x$ magnification (Alliance Microscopia, São Carlos, Brazil).

\section{Experimental groups}

\section{Group PFCP: ProDesign Logic 25/.05 +} Flatsonic (coronal and middle thirds) + Clearsonic (coronal and middle thirds) + Prodesign Logic 40\%.01 ( $n=15$ )

A size 15 K-file (Dentsply Maillefer, Ballaigues, Switzerland) was passively inserted along the working length of the root canals. The ProDesign Logic 25/.05 instrument was operated in rotating motion powered by a torque-limited electric motor (Easy Equipamentos Odontológicos, Belo Horizonte, Brazil) at $950 \mathrm{rpm}$ and $4 \mathrm{~N} / \mathrm{cm}$ torque in accordance with the manufacturer's instructions. The instrument was introduced into the root canal until resistance was felt and a brushing motion within a 3-mm amplitude limit

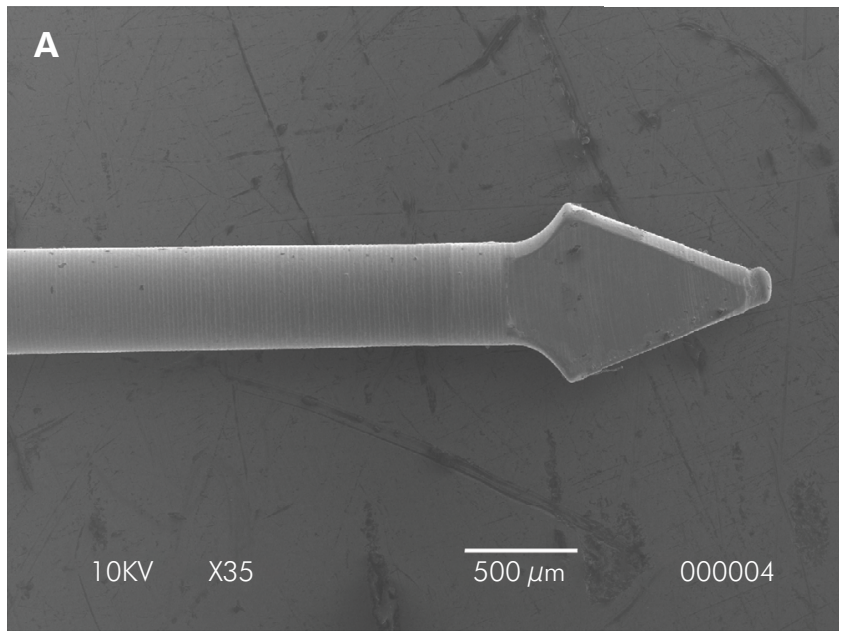

was applied three times. Subsequently, the instrument was removed and cleaned and the root canal was irrigated with $3 \mathrm{~mL}$ of $1 \%$ sodium hypochlorite $(\mathrm{NaOCl})$. This sequence was repeated until $2 / 3$ of the working length was reached. An ultrasonic tip with a flattened arrow design (Flatsonic, Helse Ultrasonic, Santa Rosa de Viterbo, Brazil) (0.25-mm diameter tip) (Figure 1A) mounted in an ultrasonic device (NSK Brasil Ltda, São Paulo, Brazil) at a frequency of $30 \mathrm{kHz}$ was used; it was activated using three cycles of 20 seconds in the buccolingual direction in order to touch these walls. The protocol for this procedure, determined after a pilot study, was repeated three times, and after each cycle, $3 \mathrm{~mL}$ of $1 \%$ sodium hypochlorite $(\mathrm{NaOCl})$ was used. This protocol was determined after a pilot study. Another ultrasonic tip with a convex arrow design (Clearsonic, Helse Ultrasonic, Santa Rosa de Viterbo, Brazil) (0.50-mm diameter tip) (Figure 1B) was used, applying the same protocol for the ultrasonic instrumentation of the root canal as previously described. The ProDesign Logic 40/.01 instrument was operated at $350 \mathrm{rpm}$ and $1 \mathrm{~N} / \mathrm{cm}$ torque in accordance with the manufacturer's instructions and under the experimental conditions described for the use of these rotary files. Afterwards, the instrument was removed and cleaned and the root canal was irrigated with $3 \mathrm{~mL}$ of $1 \%$ sodium hypochlorite $(\mathrm{NaOCl})$. This sequence was repeated

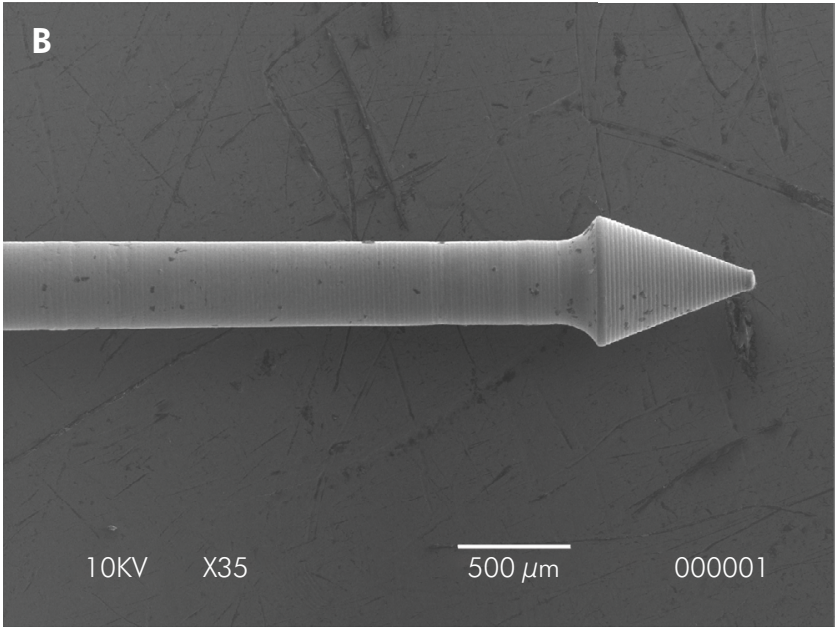

Figure 1. (A) Scanning electron microscopy (SEM) image of the Flatsonic tip (original magnification, 35x); (B) Scanning electron microscopy (SEM) image of the Clearsonic tip (original magnification, 35x). 
until the working length of the root canal was reached. Subsequently, a final irrigation protocol was used. Two milliliters of $1 \% \mathrm{NaOCl}$ was refreshed and ultrasonically activated with an ultrasonic device (NSK, Brasil Ldta, São Paulo, Brazil) using an Irrisonic tip (size 20, 0.01 taper) (Helse Ultrasonic, Santa Rosa de Viterbo, Brazil) set to low power, three times for 20 seconds each. The specimens were flushed with $17 \%$ EDTA for 3 minutes and ultrasonically activated for 60 seconds. The root canals were flushed with $2 \mathrm{~mL}$ of $1 \% \mathrm{NaOCl}$ and ultrasonically activated three times for 20 seconds each. ${ }^{22}$ The specimens were finally rinsed with saline solution and dried with sterile paper points. Thereafter, the samples were scanned for the last time using standardized parameters, as previously explained.

\section{Group FCP: Flatsonic (coronal and middle} thirds) + Clearsonic (coronal and middle thirds) + ProDesign Logic 40\%.01 ( $n=15$ )

A size $15 \mathrm{~K}$-file (Dentsply Maillefer, Ballaigues, Switzerland) was passively inserted along the working length of the root canals. Afterwards, these instruments were used under the same experimental conditions as described for Group PFCP. Then, a final irrigation protocol was used and the samples were scanned for the last time using standardized parameters, as previously mentioned.

\section{Group PP: Prodesign Logic 25/.05 + Prodesign Logic 40/.05 ( $n=15)$}

A size 15 K-file (Dentsply Maillefer, Ballaigues, Switzerland) was passively inserted along the working length of the root canals. The ProDesign Logic 25/.05 instrument was operated in rotating motion, powered by a torque-limited electric motor (Easy Equipamentos Odontológicos, Belo Horizonte, Minas Gerais, Brazil) at $950 \mathrm{rpm}$ and $4 \mathrm{~N} / \mathrm{cm}$ torque in accordance with the manufacturer's instructions. The instrument was introduced into the root canal until resistance was felt and a brushing motion within a 3-mm amplitude limit was applied three times. Subsequently, the instrument was removed and cleaned and the root canal was irrigated with $3 \mathrm{~mL}$ of $1 \%$ sodium hypochlorite $(\mathrm{NaOCl})$. This sequence was repeated until the working length was reached.
Afterwards, the ProDesign Logic 40/.05 instrument was operated at $950 \mathrm{rpm}$ and $4 \mathrm{~N} / \mathrm{cm}$ torque in accordance with the manufacturer's instructions. The instrument was introduced into the root canal until resistance was felt and a brushing motion within a 3-mm in amplitude limit was applied three times. Subsequently, the instrument was removed and cleaned and the root canal was irrigated with $3 \mathrm{~mL}$ of $1 \%$ sodium hypochlorite $(\mathrm{NaOCl})$. This sequence was repeated until the working length was reached, and a final irrigation protocol was used. Finally, the samples were scanned for the last time.

\section{Measurement of canal volume and surface area}

After the different instrumentation protocols, reconstructed images were geometrically registered with the preoperative datasets using the DataViewer software (Bruker-microCT, Kontich, Belgium) for a quantitative comparison of the morphological parameters before and after the shaping procedures..$^{23}$ Both canal volume $\left(\mathrm{mm}^{3}\right)$ and surface areas (i.e., amount of dentin removal) were measured by subtracting the scores for the treated canals from those recorded for the untreated counterparts using the CTAn v.1.12 software (Bruker-microCT, Kontich, Belgium). ${ }^{23-24}$ Matched images of the surface areas of the canals before and after the action of the endodontic instrument and/or ultrasonic tips were examined to evaluate the amount of unprepared canal wall surface after the instrumentation techniques used in this study. This parameter was expressed as a percentage of the number of static surface voxels to the total number of surface voxels. ${ }^{23,24}$ The pre- and post-instrumentation scans were superimposed to determine the percentage of increase in volume and non-instrumented surface area.

\section{Evaluation of centering ability}

According to Gambill et al., ${ }^{25}$ 'the mean centering ratio' indicates the ability of the instrument to remain centered in the canal. Using the CTAn v.1.12 software (Bruker-microCT, Kontich, Belgium), cross-sectional images of the teeth were obtained. A modification of this method was applied with the purpose of obtaining the centering ability in the buccolingual 
direction as well. The dimensions were determined by measuring the shortest distance from the edge of the unprepared canal to the edge of the tooth in the mesiodistal and buccolingual directions and by comparing these values with those measured in the prepared canals. The measurements of the distance of the points of interest were taken with the CTAn v.1.12 software (Bruker-microCT, Kontich, Belgium) for each level. ${ }^{24}$

This ratio was calculated for each section as follows:

$$
\frac{\left(X_{1}-X_{2}\right)}{\left(Y_{1}-Y_{2}\right)} \quad \text { or } \quad \frac{\left(Y_{1}-Y_{2}\right)}{\left(X_{1}-X_{2}\right)}
$$

According to our modification of the method developed by Gambill et al., ${ }^{25} \mathrm{X}_{1}$ was the shortest distance from the buccal aspect of the root to the periphery of the unprepared canal; $\mathrm{X}_{2}$ was the shortest distance from the buccal aspect of the root to the periphery of the prepared canal; $Y_{1}$ was the shortest distance from the lingual aspect of the root to the periphery of the unprepared canal; $Y_{2}$ was the shortest distance from the lingual aspect of the root to the periphery of the prepared canal. A result of ' 0 ' indicated no canal transportation.

If these numbers were not equal, the lower figure was considered as the numerator of the ratio. According to this formula, a result of ' 1 ' indicated perfect centering.

\section{Canal transportation}

To analyze the extent of canal transportation, a method designed by Gambill et al. ${ }^{25}$ was used, as well as a modification of this technique, as previously described. Transportation was evaluated at three levels (cervical, middle, and apical third) using the CTAn v.1.12 software (Bruker-microCT, Kontich, Belgium). The dimensions were determined by measuring the shortest distance from the edge of the unprepared canal to the edge of the tooth in both mesiodistal and buccolingual directions and by comparing these values with those measured in the prepared root canals.

The following formula was used for the transportation calculation:

$$
\left(X_{1}-X_{2}\right)-\left(Y_{1}-Y_{2}\right)
$$

A result of ' 0 ' indicated no canal transportation.

\section{Statistical analysis}

The Graph Pad Prism 6's (GraphPad Software, Inc., California, USA) software was used for data analysis, and the non-parametric Kruskal-Wallis and Dunn's tests were performed because of the presence of non-normal distribution, confirmed by the Shapiro-Wilk test. The significance level was set at $5 \%$.

\section{Results}

\section{Volume increase and non-instrumented surface area}

As regards the increase in volume and noninstrumented surface area, statistically significant differences between groups PFCP and PP were found in the total portion of the root canal $(p<0.05$; Table 1). Group PFCP showed the greatest percentage increase in volume $(171 \%)$ and the lowest percentage of non-instrumented surface area $(18 \%)(\mathrm{p}<0.05$; Table 1; Figure 2). On the other hand, no statistically significant differences were observed between groups PFCP and FCP. As to the percentage increase in volume at the apical third, no statistically significant differences were found between the instrumentation techniques used in this study.

Table 1. Percentage values of increase in volume in the total portion and at the apical third of the root canal and in the noninstrumented surface area in the total portion of the root canal (median, minimum-maximum).

\begin{tabular}{lccc}
\hline Group & Total (\%) & Apical third (\%) & NISA- Total (\%) \\
\hline PFCP & $171.9(57.28-383.6)^{a}$ & $30.30(9.80-138.2)^{a}$ & $18.25(7.50-37.76)^{a}$ \\
FCP & $118.4(36.55-252.2)^{a b}$ & $37.70(2.70-122.1)^{a}$ & $26.64(11.80-63.60)^{a b}$ \\
PP & $46.75(22.24-157.1)^{b}$ & $68.00(12.20-215.1)^{a}$ & $38.90(4.80-60.80)^{b}$ \\
\hline
\end{tabular}

Different letters in each column indicate statistically significant difference $(p<0.05)$; NISA: Non-instrumented surface area. 

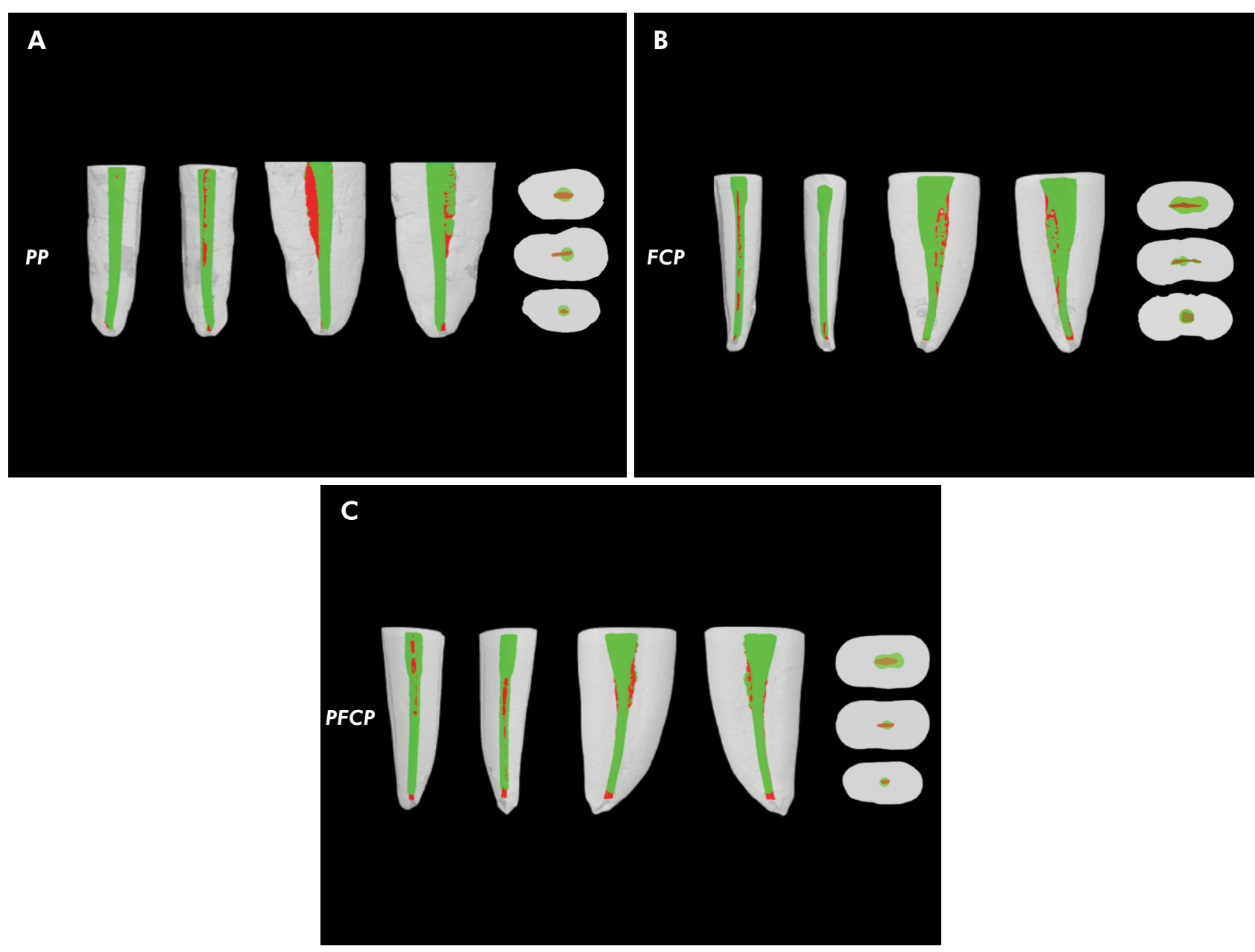

Figure 2. (A) Representative reconstructions of the superimposed specimens before (red) and after (green) endodontic instrumentation in PP. Front and side views (buccal, lingual, mesial, and distal). Representative cross-sections of the superimposed flattened/ovalshaped mandibular incisors before (red) and after (green) endodontic instrumentation in each experimental group at the coronal, middle, and apical thirds. (B) Representative reconstructions of the superimposed specimens before (red) and after (green) endodontic instrumentation in FCP - front and side views (buccal, lingual, mesial, and distal). Representative cross-sections of the superimposed flattened/oval-shaped mandibular incisors before (red) and after (green) endodontic instrumentation in each experimental group at the coronal, middle, and apical thirds. (C) Representative reconstructions of the superimposed specimens before (red) and after (green) endodontic instrumentation in PFCP. Front and side views (buccal, lingual, mesial, and distal). Representative cross-sections of the superimposed flattened/oval-shaped mandibular incisors before (red) and after (green) endodontic instrumentation in each experimental group at the coronal, middle, and apical thirds.

\section{Dentin removal}

For the mesial wall, statistically significant differences were found at the middle third between groups FCP and PP ( $<<0.05$; Table 2). Group PP provided the highest percentage of dentin removal $(17 \%)$ when compared with group FCP $(8 \%)$. No statistically significant differences were found for the mesial wall at the coronal and apical thirds. Concerning the distal wall, statistically significant differences were found only at the apical third
( $\mathrm{p}<0.05$; Table 2). Between groups FCP and PP, PP had the highest percentage of dentin removal $(23 \%)$. No statistically significant differences were found for the distal wall at the coronal and middle thirds. On the buccal wall, statistically significant differences were observed at the coronal third between groups FCP and PP $(\mathrm{p}<0.05$; Table 2$)$. As a result, the percentage of dentin removal was higher for group FCP (12\%). No statistically significant differences were found for the buccal wall at the middle third. Furthermore, 
Table 2. Percentage values of dentin removal at each third and on each wall of the root canal (median, minimum-maximum).

\begin{tabular}{|c|c|c|c|}
\hline Group & Coronal third & Middle third & Apical third \\
\hline \multicolumn{4}{|c|}{ Mesial wall } \\
\hline PFCP & $11.00(0.0-40.00)^{a}$ & $11.00(0.0-40.00)^{a b}$ & $7.00(0.0-30.00)^{a}$ \\
\hline $\mathrm{FCP}$ & $15.00(0.0-45.00)^{a}$ & $8.00(0.0-40.00)^{b}$ & $14.00(0.0-28.00)^{a}$ \\
\hline PP & $21.00(2.00-44.00)^{a}$ & $17.00(7.00-41.00)^{\circ}$ & $22.00(6.00-39.00)$ \\
\hline \multicolumn{4}{|c|}{ Distal wall } \\
\hline PFCP & $11.00(0.0-40.00)^{a}$ & $10.00(0.0-33.00)^{a}$ & $5.00(0.0-26.00)^{a}$ \\
\hline FCP & $17.00(0.0-28.00)^{a}$ & $10.00(0.0-22.00)^{a}$ & $15.00(0.0-38.00)^{a b}$ \\
\hline PP & $19.00(0.0-39.00)^{a}$ & $17.00(2.00-41.00)^{\circ}$ & $23.00(4.00-51.00)$ \\
\hline \multicolumn{4}{|c|}{ Buccal wall } \\
\hline PFCP & $10.00(0.0-29.00)^{a b}$ & $4.00(0.0-35.00)^{a}$ & $0.00(0.0-24.00)^{a}$ \\
\hline $\mathrm{FCP}$ & $12.00(0.0-39.00)^{b}$ & $2.00(0.0-46.00)^{a}$ & $6.00(0.0-56.00)^{a b}$ \\
\hline PP & $3.00(0.0-12.00)^{a}$ & $7.00(0.0-11.00)^{a}$ & $18.00(0.0-57.00)^{b}$ \\
\hline \multicolumn{4}{|c|}{ Lingual wall } \\
\hline PFCP & $26.00(0.0-50.00)^{a}$ & $4.00(0.0-26.00)^{a}$ & $7.00(0.0-49.00) a b$ \\
\hline $\mathrm{FCP}$ & $25.00(5.0-47.00)^{a}$ & $5.00(0.0-9.00)^{a}$ & $10.00(0.0-22.00)^{b}$ \\
\hline PP & $7.00(0.0-21.00)^{b}$ & $8.00(0.0-17.00)^{a}$ & $18.00(6.00-42.00)$ \\
\hline
\end{tabular}

statistically significant differences were observed between groups PFCP and PP at the apical third of the root canal. In this case, the highest percentage of dentin removal was produced by the instrumentation protocol used in group PP (18\%). As regards the lingual wall, statistically significant differences were found at the coronal third $(\mathrm{p}<0.05$; Table 2). When compared with groups PFCP and FCP, group PP showed the lowest percentage of dentin removal (7\%). No statistically significant differences were observed at the middle third of the root canal between the instrumentation protocols used in this study. At the apical third of the lingual wall, statistically significant differences were found between groups FCP and PP, at which group PP showed the highest percentage of dentin removal (18\%).

\section{Transportation values}

In the buccolingual direction, transportation occurred in the lingual aspect of the root in most of the instrumented root canals, showing statistically significant differences between groups PFCP and $\mathrm{PP}$ at the coronal third of the root canal ( $\mathrm{p}<0.05$; Table 3). PP showed the lowest transportation values. No statistically significant differences were found at the middle and apical thirds. In the mesiodistal direction, no statistically significant differences were found at the coronal, middle, and apical thirds between the three instrumentation protocols used in this study ( $p<0.05$; Table 3$)$.

\section{Centering ratio}

In the buccolingual direction, statistically significant differences were observed between groups PFCP and PP and between groups FCP and $\mathrm{PP}$ at the coronal third of the root canal $(\mathrm{p}<0.05$; Table 3). Thus, PP showed the highest centering ratio at the coronal third of the root canals prepared with the three instrumentation protocols evaluated in this study. No statistically significant differences were found at the middle third of the root canals. At the apical third, statistically significant differences were observed between groups PFCP and PP. Therefore, group PFCP displayed the highest centering ratio. In the mesiodistal direction, no statistically significant differences were observed at the coronal third between the three instrumentation protocols used in this study $(p<0.05$; Table 3). However, statistically significant differences were found between groups FCP and $\mathrm{PP}$ at the middle third of the root canal. The highest 
Table 3. Canal transportation after different instrumentation protocols. A result of ' $O$ ' indicates no canal transportation. A result of 1 indicates perfect centering ability (Mean \pm SD).

\begin{tabular}{lcccccc}
\hline \multirow{2}{*}{ Group } & \multicolumn{3}{c}{ Transportation } & & \multicolumn{2}{c}{ Centering ratio } \\
\cline { 2 - 7 } & Coronal third & Middle third & Apical third & Coronal third & Middle third & Apical third \\
\hline B/L & & & & & & \\
PFCP & $-0.426 \pm 0.425^{a}$ & $0.074 \pm 0.276^{a}$ & $-0.180 \pm 0.435^{a}$ & $-0.505 \pm 0.368^{a}$ & $-0.843 \pm 0.228^{a}$ & $-1.133 \pm 0.452^{a}$ \\
FCP & $-0.342 \pm 0.402^{\mathrm{ab}}$ & $0.009 \pm 0.263^{a}$ & $0.076 \pm 0.346^{a}$ & $-0.460 \pm 0.301^{a}$ & $-0.925 \pm 0.143^{a}$ & $-0.753 \pm 0.292^{\mathrm{ab}}$ \\
PP & $-0.125 \pm 0.172^{\mathrm{b}}$ & $-0.030 \pm 0.146^{a}$ & $-0.023 \pm 0.249^{a}$ & $-0.915 \pm 0.165^{\mathrm{b}}$ & $-0.864 \pm 0.13^{a}$ & $-0.455 \pm 0.431^{b}$ \\
M/D & & & & & & \\
PFCP & $0.013 \pm 0.181^{a}$ & $-0.012 \pm 0.145^{a}$ & $0.007 \pm 0.095^{a}$ & $-0.746 \pm 0.252^{a}$ & $-0.762 \pm 0.149^{a b}$ & $-0.912 \pm 0.179^{a}$ \\
FCP & $0.004 \pm 0.197^{a}$ & $0.012 \pm 0.174^{a}$ & $-0.020 \pm 0.102^{a}$ & $-0.635 \pm 0.215^{a}$ & $-0.806 \pm 0.156^{b}$ & $-0.783 \pm 0.130^{a b}$ \\
PP & $0.002 \pm 0.108^{a}$ & $0.036 \pm 0.093^{a}$ & $-0.045 \pm 0.157^{a}$ & $-0.539 \pm 0.252^{a}$ & $-0.612 \pm 0.198^{a}$ & $-0.567 \pm 0.218^{b}$ \\
\hline
\end{tabular}

B/L: Buccolingual direction; M/D: Mesiodistal direction; Different letters in each of the B/L or M/D columns separately indicate statistically significant difference $(p<0.05)$; Positive values indicate buccal or mesial direction of transportation; Negative values indicate lingual or distal direction of transportation.

centering ratio was displayed by the instrumentation protocol used in group FCP. At the apical third, statistically significant differences were observed between groups PFCP and PP. Therefore, group PFCP displayed the highest centering ratio.

\section{Discussion}

In the present study, the effect of novel ultrasonic tips as an auxiliary method for the rotary preparation of flattened/oval-shaped canals with the aid of the dental operating microscope was evaluated by $\mu \mathrm{CT}$. The present study considered several variables: changes in volume and surface area, centering ability, degree of canal transportation, and percentage of dentin removal produced by different instrumentation protocols. These protocols included the combination of rotary $\mathrm{CM}$ instruments with ultrasonic tips. The influence of these protocols on the instrumentation of flattened/oval-shaped canals was determined by $\mu \mathrm{CT}$ scans. $\mu \mathrm{CT}$ imaging is a high-resolution research tool that allows the development of accurate three-dimensional models and the acquisition of quantitative data. ${ }^{15}$ This technology has been described as noninvasive and serves as a reproducible method for the analysis of different shaping techniques without destroying the samples. ${ }^{26-27}$ In the same way, the use of the dental operating microscope has been widely accepted as an important technological asset in endodontics. ${ }^{28,29,30,31,32}$
Proper biomechanical preparation of the root canal space is essential for a successful endodontic therapy. ${ }^{33}$ The shaping and cleaning of ovalshaped canals represent a challenge because these root canals tend to have a greater buccolingual dimension and endodontic instruments tend to remain at the center of the canal. ${ }^{11,19,34}$ This leads to non-instrumented areas that could influence the outcome of the treatment. ${ }^{11,13,19}$ However, it has been observed that the efficacy of instrumentation is closely associated with the canal anatomy and pathosis than with the use of any mechanical devices. ${ }^{35}$ Ultrasonic instrumentation has been proposed as an alternative debridement approach, in combination with endodontic instruments, for improved cleaning of the root canal system. ${ }^{17-18,33,36}$ The different instrumentation protocols used in this study produced significant gains in canal volume and surface area, resulting in considerable reduction of non-instrumented areas (Table 1; Figure 2). The use of new auxiliary methods should favorably influence the treatment prognosis. ${ }^{35}$ The instrumentation technique applied in group PFCP produced the highest increase in volume in the total portion of the root canal and showed the lowest percentage of non-instrumented surface area $(p<0.05)$. These results suggested that when a rotary instrument (ProDesign Logic 25/.05) was used prior to the ultrasonic tips (Flatsonic and Clearsonic), there was a significant reduction in the percentage of non- 
instrumented surface area (18\%). Therefore, the use of an engine-driven instrument to create a glide path is recommended to aid the action of the Flatsonic tip with its flattened design and a diameter of 0.25 $\mathrm{mm}$ in anatomically complex areas. This protocol facilitated the use of the Clearsonic tip, which has a 0.5 -mm diameter, corresponding to ISO file size 50. However, no statistically significant differences were found between groups PFCP and FCP, indicating that both protocols in which ultrasonic tips were used showed identical and favorable results. A higher percentage of increase in volume provided a lower percentage of non-instrumented areas and may improve the cleaning of the root canal system. Similarly, no statistically significant differences were found between the experimental groups when the percentage of increase in volume at the apical third was evaluated. These results could be explained by the use of only rotary instruments at the apical third. Weller et al..$^{18}$ observed similar results in a study in which the use of ultrasound after manual instrumentation contributed $88 \%$ (in human teeth) to $92 \%$ (in resin blocks) to debridement when loss of radioactivity was measured. Since this is the first study considering the association of these rotary files with ultrasonic tips for the shaping of oval-shaped root canals, the presence of discrepancies in experimental designs and results between studies should be emphasized.

Canal volume is a variable used to analyze the effects of canal instrumentation on dentin removal. ${ }^{24}$ Relative to the mesial wall, the statistically significant differences at the middle third could be explained by the use of ProDesign Logic 25/.05 and ProDesign Logic 40/.05 files in PP, which produced a greater wear in this portion of the root $(p<0.05$; Table 2$)$. Concerning the distal wall, statistically significant differences were only found at the apical third, where PP also showed the highest percentage of dentin removal. These results could be explained by the use of an instrument of a larger taper in this region. The larger the taper, the higher the amount of prepared surface area in the root canal walls. ${ }^{14}$ Larger apical preparations have been associated with improvements in disinfection and cleaning procedures, reducing the bacterial load in the root canal system. ${ }^{14}$ Regarding the buccal wall, statistically significant differences were observed at the coronal third between groups FCP and PP, where the protocol used in group FCP demonstrated a significant increase in dentin removal. These results might be related to the use of the ultrasonic tips before the creation of a glide path with an engine-driven instrument and to their direction of action in the buccolingual plane. At the apical third, the greatest percentage of dentin removal was detected in the protocol in which only rotary instruments (Group PP) were used. Concerning the lingual wall, statistically significant differences were observed at the coronal third for group PFCP, which was possibly related to the direction of action of the ultrasonic tips in the buccolingual plane. However, statistically significant differences were found at the apical third, where only rotary instruments (Group PP) were used, showing the greatest percentage of dentin removal. These results could be associated with the use of ProDesign Logic 40/.05, which has a greater taper, being more rigid and producing a greater wear in this area. ${ }^{21}$

As to the buccal and lingual walls, statistically significant differences were observed at the coronal third, where the use of ultrasonic tips demonstrated a significant increase in dentin removal, related to their direction of action in the buccolingual plane. However, statistically significant differences were found at the apical third, where only rotary instruments (Control Group: PP) were used and the highest percentage of dentin removal was detected.

As far as transportation values are concerned, statistically significant differences were observed between groups PFCP and PP at the coronal third of the root canal, where PP showed the lowest transportation values ( $p<0.05$; Table 3 ). These results were associated with the protocol without the use of ultrasonic tips as an auxiliary method for shaping oval-shaped root canals and they could be explained by the use of ultrasonic tips in the buccolingual direction, which had greater action in this region. This suggests that ultrasonic tips should be used with caution at the coronal third. These results were in agreement with those of another study, in which the Prodesign Logic system showed one of the lowest transportation values at the coronal third. ${ }^{37}$ Regarding transportation values 
at the middle and apical thirds in the buccolingual direction, no statistically significant differences were found. On the other hand, in the mesiodistal direction, no statistically significant differences were observed between the three experimental groups, at the coronal, middle, and apical thirds. Consequently, all the protocols showed a satisfactory performance concerning transportation values in this study. The results of this study are at odds with those of other traditional publications, in which ultrasonic instrumentation created an irregular shape in the root canal, particularly 3 to $6 \mathrm{~mm}$ from the root apex. ${ }^{38,39}$ However, when compared with the current study, those investigations differed in technological advances and in the experimental designs used by the authors.

In this study, the centering ability of these new protocols for the instrumentation of flattened/ovalshaped canals was tested (Table 3). Thus, in the buccolingual direction, PP showed the highest centering ratio at the coronal third of the root canals prepared with the three instrumentation protocols evaluated in this study. In this group, only rotary instruments were used, and the literature has revealed that NiTi instruments produced few changes in canal anatomy during shaping of the root canal system. ${ }^{37}$ These results could be associated with activation of the ultrasonic tips in the buccolingual direction, as previously mentioned. Notwithstanding, all of the techniques used in this study proved to be safe regarding their centering ability. No statistically significant differences were found at the middle third of the root canals. At the apical third, statistically significant differences were observed between groups PFCP and PP. Therefore, group PFCP displayed the highest centering ratio. This could be explained by the use of ProDesign Logic 40/.01 file in group PFCP, in contrast with ProDesign Logic 40/.05, which has a larger taper. This makes ProDesign Logic 40/.05 more rigid and may produce greater wear in this area. ${ }^{21}$ In the mesiodistal direction, no statistically significant differences were observed at the coronal third between the three instrumentation protocols used in this study. However, statistically significant differences were found between groups FCP and PP at the middle third of the root canal. The highest centering ratio was displayed by the instrumentation protocol used in group FCP. This implied that the use of ultrasonic tips combined with ProDesign Logic $40 / .01$ provided a more centered preparation at the middle third of the root canal than the protocol in which ProDesign Logic 25/.05 and ProDesign Logic $40 / .05$ were used. These results could be related to the presence of flattened areas in oval-shaped canals and to the action of an instrument with a larger taper in this portion of the root, which may produce greater lateral cutting. ${ }^{21}$ At the apical third, statistically significant differences were observed between groups PFCP and PP. Therefore, group PFCP displayed the highest centering ratio, explained by the use of ProDesign Logic 40/.01 file in group PFCP, in contrast with ProDesign Logic 40/.05, which had a larger taper.

\section{Conclusion}

Based on the experimental design of this study, the null hypothesis that novel ultrasonic tips would not influence the instrumentation of flattened/oval-shaped root canals was rejected. These protocols showed an adequate performance regarding the centering ratio and degree of canal transportation. The combination of rotary instruments with ultrasonic tips increases canal volume and surface, reducing the non-instrumented areas of the root canal system.

\section{Acknowledgments}

The authors deny any conflicts of interest.

\section{References}

1. Mauger MJ, Schindler WG, Walker WA. An evaluation of canal morphology at different levels of root resection in mandibular incisors. J Endod. 1998 Sep;24(9):607-9. https://doi.org/10.1016/S0099-2399(98)80120-9 
2. Wu MK, R'Oris A, Barkis D, Wesselink PR. Prevalence and extent of long oval canals in the apical third. Oral Surg Oral Med Oral Pathol Oral Radiol Oral Endod. 2000 Jun;89(6): 739-43. https://doi.org/10.1067/moe.2000.106344

3. Versiani MA, Pécora JD, Sousa-Neto MD. Flat-oval root canal preparation with self-adjusting file instrument: a micro-computed tomography study. J Endod. 2011 Jul;37(7):1002-7. https://doi.org/10.1016/i.joen.2011.03.017

4. Almeida MM, Bernardineli N, Ordinola-Zapata R, Villas-Bôas MH, Amoroso-Silva PA, Brandão CG, et al. Micro-computed tomography analysis of the root canal anatomy and prevalence of oval canals in mandibular incisors. J Endod. 2013 Dec;39(12):1529-33. https://doi.org/10.1016/i.joen.2013.08.033

5. Azim AA, Piasecki L, Neto UXS, Cruz ATG, Azim KA. Xp shaper, a novel adaptive core rotary instrument: micro-computed tomographic analysis of its shaping abilities. J Endod. 2017; 43(9):1532-8. https://doi.org/10.1016/i.joen.2017.04.022

6. Wu MK, Sluis LW, Wesselink PR. The capability of two hand instrumentation techniques to remove the inner layer of dentine in oval canals. Int Endod J. 2003 Mar; 36(3): 218 -24. https://doi.org/10.1046/i.1365-2591.2003.00646.x

7. Weiger R, ElAyouti A, Löst C. Efficiency of hand and rotary instruments in shaping oval root canals. J Endod. 2002 Aug;28(8):580-3. https://doi.org/10.1097/00004770-200208000-00004

8. Zmener O, Pameijer CH, Banegas G. Effectiveness in cleaning oval-shaped root canals using anatomic endodontic technology, profile and manual instrumentation: a scanning electron microscopic study. Int Endod J. 2005 Jun; 38(6):356-63. https://doi.org/ 10.1111/j.1365-2591.2005.00938.x

9. Zmener $\mathrm{O}$, Pameijer $\mathrm{CH}$, Banegas $\mathrm{G}$. Retreatment efficacy of hand versus automated instrumentation in oval-shaped root canals: an ex vivo study. Int Endod J. 2006 Jul;39(7):521-6. https://doi.org/ 10.1111/j.1365-2591.2006.01100.x

10. Rüttermann S, Virtej A, Janda R, Raab WH. Preparation of the coronal and middle third of oval root canals with a rotary or an oscillating system. Oral Surg Oral Med Oral Pathol Oral Radiol Endod. 2007 Jun; 104(6):852-6. https://doi.org/10.1016/j.tripleo.2007.04.030

11. Coniglio I, Carvalho CA, Magni E, Cantoro A, Ferrari M. Post space debridement in oval-shaped canals: The use of a new ultrasonic tip with oval section. J of Endod 2008 Jun;34(6):752-5. https://doi.org/10.1016/i.joen.2008.03.017

12. De-Deus G, Murad C, Paciornik S, Reis CM, Coutinho-Filho T. The effect of the canal-filled area on the bacterial leakage of oval-shaped canals. Int Endod J. 2008 Mar; 41(3):183-90. https://doi.org/10.1111/i.1365-2591.2007.01320.x

13. Zuolo ML, Zaia AA, Belladonna FG, Silva EJLN, Souza EM, Versiani MA, et al. Micro-ct assessment of the shaping ability of four root canal instrumentation systems in oval-shaped canals. Int Endod J. 2018 May; 51(5):564-71. https://doi.org/10.1111/iej.12810

14. De-Deus G, Belladonna FG, Silva EJNL, Marins JR, Souza EM, Perez R, et al. Micro-ct evaluation of non-instrumented canal areas with different enlargements performed by niti systems. Braz Dent J. 2015 Jun; 26(6):624-9. http://dx.doi.org/10.1590/0103-6440201300116

15. Versiani MA, Ordinola-Zapata R, Keleş A, Alcin H, Bramante CM, Pécora JD, et al. Middle canals in mandibular first molars: a micro ct study in different populations. Arch Oral Biol. 2016 Jan; 61:130-7. https://doi.org/10.1016/i.archoralbio.2015.10.020

16. Peters OA, Bahia MGA, Pereira ESJ. Contemporary root canal preparation. Dent Clin North Am. 2017 Jan;61(1):37-58. https://doi.org/10.1016/i.cden.2016.08.002.

17. Lumley PJ, Walmsley AD, Walton RE, Rippin JW. Cleaning of oval canals using ultrasonic or sonic instrumentation. J Endod. 1993 Sep; 19(9):453-7. https://doi.org/10.1016/S0099-2399(06)80532-7

18. Weller N, Brady JM, Bernier WE. Efficacy of ultrasonic cleaning. J Endod. 1980 Sep; 6(9):740-43. https://doi.org/10.1016/S0099-2399(80)80185-3

19. Coelho BS, Amaral ROJFD, Leonardi DP, Marques-da-Silva B, Silva-Sousa YTC, Carvalho FMAD, et al. Performance of three single instrument systems in the preparation of long oval canals. Braz Dent J. 2016 Feb;27(2):217-22. http://dx.doi.org/10.1590/01036440201302449

20. Ahmed HMA, Versiani MA, De Deus G, Dummer PMH. A new system for classifying root and root canal morphology. Int Endod J 2017 Aug;50(8):761-70. https://doi.org/10.1111/iej.12685

21. ElAyouti A, Chu AL, Kimionis I, Klein C, Weiger R, Löst C. Efficacy of rotary instruments with greater taper in preparing oval root canals. Int Endod J. 2008 Dec;41(12):1088-92. https://doi.org/10.1111/j.1365-2591.2008.01475.x

22. van der Sluis LWM, Vogels MPJM, Vergaagen B, Macedo R, Wesselink PR. Study on the influence of refreshment/activation cycles and irrigants on mechanical cleaning efficiency during ultrasonic activation of the irrigant. J Endod. 2010 Apr; 36(4):737-40. https://doi.org/10.1016/i.joen.2009.12.004

23. Amoroso-Silva P, Alcalde MP, Húngaro-Duarte MA, De-Deus G, Ordinola-Zapata R, Freire LG, et al. Effect of finishing instrumentation using niti hand files on volume, surface area and uninstrumented surfaces in c-shaped root canal systems. Int Endod J. 2017 Jun;50(6):604-11. https://doi.org/10.1111/iej.12660

24. Gergi R, Osta N, Bourbouze G, Zgheib C, Arbab-Chirani R, Naaman A. Effects of three nickel titanium instruments systems on root canal geometry assessed by micro-computed tomography. Int EndodJ. 2015 Feb;48(2):162-70. https://doi.org/10.1111/iej.12296

25. Gambill J, Alder MA, del Rio CE. Comparison of nickel-titanium and stainless steel hand-file instrumentation using computed tomography. J Endod. 1996 Jul;22(7):369-75. https://doi.org/10.1016/S0099-2399(96)80221-4 
- Ultrasonic tips as an auxiliary method for the instrumentation of oval-shaped root canals

26. Rhodes JS, Ford TR, Lynch JA, Liepins PJ, Curtis RV. Micro-computed tomography: a new tool for experimental endodontology. Int Endod J. 1999 Mar; 32(3):165-70. https://doi.org/10.1046/i.13652591.1999.00204.x

27. Peters $O A$, Laib A, Rüegsegger $P$, Barbakow F. Three-dimensional analysis of root canal geometry by high-resolution computed tomography. J Dent Res. 2000 Jun;79(6):1405-9. https://doi.org/10.1177/00220345000790060901

28. Carr GB, Murgel CAF. The use of the operating microscope in endodontics. Dent Clin North Am. 2010;54(2):191-214. https://doi.org/10.1016/i.cden.2010.01.002

29. Perrin P, Neuhaus KW, Lussi A. The impact of loupes and microscopes on vision in endodontics. Int Endod J. 2014 May; 47(5):425-9. https://doi.org/10.1111/iej.12165

30. Michaelides PL. Use of the operating microscope in dentistry. J Calif Dent Assoc. 1996 Jun;24(6):45-50.

31. Wu D, Shi W, Wu J, Wu Y, Liu W, Zhu Q. The clinical treatment of complicated root canal therapy with the aid of a dental operating microscope. Int Dent J. 2011 May;61(5):261-6. https://doi.org/10.1111/j.1875-595X.2011.00070.x

32. Mittal S, Kumar T, Sharma J, Mittal S. An innovative approach in microscopic endodontics. J Conserv Dent. 2014 Mar; 17(3):297-8. https://doi.org/10.4103/0972-0707.131812

33. Goldman M, White R, Moser CR, Tenca JI. A comparison of three methods of cleaning and shaping the root canal in vitro. J Endod. 1988 Jan;14(1):7-12. https://doi.org/10.1016/S0099-2399(88)80235-8

34. Busquim S, Cunha RS, Freire L, Gavini G, Machado ME, Santos M. A micro-computed tomography evaluation of long-oval canal preparation using reciprocating or rotary systems. Int Endod J. 2015 Oct;48(10):1001-6. https://doi.org/10.1111/iej.12398

35. Langeland K, Liao K, Pascon EA. Work-saving devices in endodontics: efficacy of sonic and ultrasonic techniques. J Endod. 1985 Nov;11(11):499-510. https://doi.org/10.1016/S0099-2399(85)80223-5

36. Singh R, Barua P, Kumar M, Safaya R, Monajemi H, Monajemi H. Effect of ultrasonic instrumentation in treatment of primary molars. J Contemp Dent Pract. 2017 Sep;18(9):750-53. https://doi.org/10.5005/ip-journals-10024-2120

37. Pinheiro SR, Alcalde MP, Vivacqua-Gomes N, Bramante CM, Vivan RR, Duarte MAH, et al. Evaluation of apical transportation and centering ability of five thermally treated niti rotary systems. Int Endod J. 2018 Jun; 51(6):705-713. https://doi.org/10.1111/iej.12881

38. Moriya K. Fundamental study of root canal preparation by ultrasonic system. Jpn J Conserv Dent. 1984;27:333-60.

39. Yamaguchi M, Matsumori M, Ishikawa $H$, Sakurai T, Nakamura $H$, Naitoh M, et al. The use of ultrasonic instrumentation in the cleansing and enlargement of the root canal. Oral Surg Oral Med Oral Pathol. 1988 Mar; 65(3):349-53.

https://doi.org/10.1016/0030-4220(88)90121-1 